\title{
Work environment and employee performance: a brief literature review
}

\author{
Mehrsa Bakhtiyari ${ }^{1}$ \\ ${ }^{1}$ Affiliation not available
}

April 28, 2020

Mehrsa Bakhtiyari ${ }^{1 *}$

1 Department of Management, Tehran Markaz Azad University, Tehran, Iran.

* Correspondence: mehrsa.bakhtiari@yahoo.com

\begin{abstract}
Work environment can either be conducive or toxic. They affect employee performance in several ways. In this study, a brief literature review on the environmental factors affecting employee performance is presented.
\end{abstract}

\section{Introduction}

Work environment can be divided into two components: physical and behavioral. The physical environment consists of elements that relate to the office occupiers' ability to physically connect with their office environment while the behavioral environment consists of components that relate to how well the office occupiers connect with each other, and the impact the office environment can have on the behavior of the individual.

According to Haynes (2008), the physical environment with the productivity of its occupants falls into two main categories: office layout (open-plan versus cellular offices) and office comfort (matching the office environment to the work processes), and the behavioral environment represents the two main components namely interaction and distraction.

These components can further be divided in major attributes and operationalized in the form of different independent variables. These variables will be used for analysis of their impact on dependent variables. It is generally understood that the physical design of offices and the environmental conditions at work places are important factors in organizational performance.

Studies have examined the effect of physical work environment on workers' job satisfaction, performance, and health. Scott (2000) reported that working condition is associated with employees' job involvement and job satisfaction.

Michie et al (1999) in a study observed that social, organizational and physical context serve as the impetus for tasks and activities, and considerably influence workers' performance. Studies on the quality of work life have also established the importance of safe and healthy working conditions in determining employees' job performance.

The influence of work environment, which is mostly composed of physical, social and psychological factors, has been extensively examined in past two decades. In a number of studies, employees' motivation, job satisfaction, job involvement, job performance, and health have been found to be markedly influenced by psycho-social environment of work organization. 
According to Burke (1992), performance relies on internal motivation but presence of internal factors such as necessary skills, intellectual capacity and resources to do the job clearly have an impact. As a consequence, employers are supposed to provide appropriate working conditions in order to make sure the performance of employees meet the required standards.

Work environment, according to Opperman (2002), is a composite of three major sub-environments via: the technical environment, the human environment and the organizational environment. Technical environment refers to tools, equipment, technological infrastructure and other physical or technical elements. This is a basis to attain maximum productivity. Organizational environment includes systems, procedures, practices, values and philosophies.

Kyko (2005) posited that there are two types of work environment. These are identified as conducive work environment and toxic work environment. Conducive work environment gives pleasurable experience to employees and enable them to actualize their abilities and potentials. It also reinforces self-actualizing behaviour. For instance, an irresponsible employee changing into a responsible employee in a conducive work environment. Toxic environment according to him brings about unpleasant experiences and at the same time, de-actualize employees' behaviour. It reinforces low self-actualizing behaviours and leads to the development of negative traits of the employees. However, in a toxic work environment, responsible and sensible employee can change into irrational and irresponsible employee as a survival strategy (Kyko, 2005). He identified six factors which contribute to a toxic work environment hence contributing to low performance of employees. These factors are opaque management, biased boss, and organizational policies, working conditions, interpersonal relationship and pay.

Work environment is a mixture of many factors, which when come together form the environment of an organization. These factors are: - goal setting, workplace incentives, defined processes, performance feedback, Role congruity, mentoring, resource availability and supervisor support. All these factors together have an impact on the performance of an employee. Therefore, in order to gain better results from the employees, it becomes very essential that they should be provided with proper work environment factors. Goal setting, for every employee is a very important task and employees want that they should also be involved in setting their goals and performance measures. This factor can easily be taken care of by deciding these factors through an informal meet between the employee and his/her supervisor. This will allow all the employees to be a part of their goal setting procedure, which will influence the employees to perform well in order to achieve goals set by them. Another important factor for creating a good work environment is to provide employees with regular feedback on their performance. The feedback should include both the negative and positive aspects of the employee's performance. It should not be so that only the mistakes of an employee are being pointed but good performance done by an employee should also be appreciated. Organization should take care that the delivery of the feedback is appropriate, so that the employee does not feel awful after getting a negative feedback. Areas where he/she should improve should be made clear in the feedback so that the employee can improve upon his/her skills. Next important factor, in order to provide an employee with a cordial environment, is to provide the employee with a job which complies with his/her expectations from the job. The job description and the role which the employee is supposed to perform should be in uniformity with the tasks allocated by the manager. Not only this, the processes of performing the tasks should also be well defined. The process management should be proper and any requirements of the job should be properly communicated to the employee (Arnold, 2005). An essential requirement of the employees is that they want to learn more and enhance their skills. If a job is not enriching their skills, then they might not be interested in doing that job. Therefore, it is very important that the employees be provided with regular trainings in order to enhance their existing skills and developing new skills. Another important factor to create a better work environment is resource availability. Employees should be provided with required resources so that they can perform well. All the above mentioned factors are required to be present in an organization in order to provide the employees with a good working environment. Cancelliere (2011) emphasized that it would be helpful for employers and decision makers to study and apply research evidence to consider environmental design as an investment in the workforce. 


\section{Employee performance and its relation to environmental factors}

Environmental factors have a direct effect on employees' performance. These factors are discussed below.

\section{Defined processes}

The organization constrains the variability of how work is actually performed through documenting processes and communicating such expectations to employees. The organization verifies on a regular or random basis that the work is actually performed in the way required.

\section{Supervisor support}

Immediate supervisors act as advocates for employees, gathering and distributing the resources needed by employees in order for them to be able to do a good job and providing positive encouragement for a job well done. Supervisors display the interpersonal skills required to engage employees and enhance their selfconfidence.

\section{Opportunity to apply}

Time and material resources are available to employees, enabling them to perform to the best of their ability. Individual workloads and organizational systems and processes do not hinder employees from applying established skills or from practicing newly learned skills.

\section{Goal-setting}

Employees are involved in setting meaningful goals and performance measures for their work. This can be done informally between the employee and their immediate supervisor or as part of an organization's formal performance management process. The key here is that each employee is actively engaged in the goal-setting process and takes ownership of the final agreed goals and measures.

\section{Role congruity}

The role that the employee is required to perform is consistent with their expectations on joining the organization and any subsequent training. The organization's role expectations are typically reflected in formal documents, such as job descriptions and role specifications. These expectations are consistent with tasks allocated by the employee's immediate supervisor.

\section{Performance feedback}

Information on how the employee is performing is fed back regularly to employees. This consists of both positive feedbacks on what the employee is doing right as well as feedbacks on what requires improvement. The feedback is objective and delivered with the appropriate interpersonal and conflict resolution skills and can be a mix of both informal feedback and feedback delivered as part of a formal performance management cycle.

\section{Job aids}

The work environment is set up so that templates, guides, models, checklists and other such workplace aids are readily available to help minimize error rates and customer dissatisfaction. Each of these nine factors is significant in its own right. Taken together, they form a powerful coalition for maximizing the motivation, performance and productivity of your employees.

\section{Mentoring}

Skilled and respected people are available to employees to help them perform better in their current role and to assist them develop further into a future role. Mentors and coaches may be internal to an organization or external. Either way, they possess the necessary facilitation skills to assist employees develop and apply new skills.

\section{Workplace incentives}


The organization has determined what motivates its employees and has set up formal and informal structures for rewarding employees that behave in the way required. Rewards may consist of a mix of internal rewards, such as challenging assignments, and external rewards, such as higher compensation and peer recognition.

\section{Conclusion}

Work environment impacts greatly on performance of employees both positively and negatively. A conducive work environment gives satisfying experience to employees and enable them to actualize their abilities and potentials. In addition, it also reinforces self-actualizing behaviour. Therefore, to boost work performance, the different factors affecting employees' performance in the workplace as highlighted in this study should be applied by managers.

\section{References}

Arnold E. Managing human resources to improve employee retention. The Health Care Manager. 2005;24(2):13240.

Burke WW, Litwin GH. A causal model of organizational performance and change. Journal of management. 1992;18(3):523-45.

Cancelliere C, Cassidy JD, Ammendolia C, Côté P. Are workplace health promotion programs effective at improving presenteeism in workers? A systematic review and best evidence synthesis of the literature. BMC public health. 2011;11(1):395.

Haynes BP. An evaluation of the impact of the office environment on productivity. Facilities. 2008;26(5/6):17895.

Kyko OC. Instrumentation: Know Yourself and Others. 2005.

Michie S, West MA. Managing people and performance: an evidence based framework applied to health service organizations. International journal of management reviews. 2004;5(2):91-111.

Opperman CS. Tropical business issues. Partner Price Water House Coopers. International Business Review. 2002 .

Scott D, Bishop JW, Chen X. An examination of the relationship of employee involvement with job satisfaction, employee cooperation, and intention to quit in US invested enterprise in China. The international journal of organizational analysis. 2003;11(1):3-19. 